\title{
Extensive spinal epidural immature teratoma in an infant: case report
}

\author{
Fumitaka Yoshioka, MD, ${ }^{1}$ Shoko Shimokawa, MD, PhD,1 Jun Masuoka, MD, PhD,1 \\ Tomoko Izaki, MD, PhD, ${ }^{2}$ Yukiko Nakahara, MD, PhD, ${ }^{1}$ Masatou Kawashima, MD, PhD, ${ }^{3}$ \\ Shuji Sakata, MD, PhD, ${ }^{4}$ and Tatsuya Abe, MD, PhD ${ }^{1}$
}

\begin{abstract}
'Department of Neurosurgery, School of Medicine, Saga University, Saga; ${ }^{2}$ Department of Pediatric Surgery, Reproductive and Developmental Medicine, Faculty of Medical Sciences, Kyushu University, Fukuoka; ${ }^{2}$ Department of Neurosurgery, School of Medicine, International University of Health and Welfare, Chiba; and ${ }^{4}$ Department of Neurosurgery, Saga-ken Medical Centre Koseikan, Saga, Japan
\end{abstract}

\begin{abstract}
Here, the authors present an extremely rare case of an extensive spinal epidural teratoma (SET) in an infant and provide a review of the cases in the literature. In this report, the authors focused on the clinical manifestation and management of extensive SET. A 64-day-old girl presented with severe dyspnea and paraparesis caused by a large thoracic mass. Imaging studies revealed that the mass originated from the epidural space of the thoracic spine and extended from C7 to L1. The tumor extended bilaterally through the intervertebral foramina and formed a large posterior mediastinal mass. The tumor was partially resected via laminotomy after an emergency thoracotomy. The remnant grade I immature teratoma grew rapidly. After a re-laminotomy and bilateral thoracotomy, the residual tumor stopped growing. However, the patient's paraparesis improved very little, and her scoliosis progressed gradually. Therefore, SET should be included in the differential diagnosis when an infant patient with paraparesis of the lower extremities is encountered. Timely diagnosis, aggressive treatment, and close monitoring are of critical importance to successful recovery in such patients.
\end{abstract}

https://thejns.org/doi/abs/10.3171/2018.4.PEDS17676

KEYWORDS spinal epidural teratoma; extensive teratoma; infant; immature teratoma; spine; oncology

$\mathrm{S}$ PINAL teratomas account for $0.15 \%-0.18 \%$ of all spinal tumors, ${ }^{14,17} 11 \%$ of which are located in the epidural region. ${ }^{12}$ The incidence of spinal teratoma in children and infants is relatively high, $3,5,9,10$ but the characteristics of spinal epidural teratoma (SET) in infants have not been clearly reported because of the very small number of cases; only 7 cases of SET in infants have been reported in the literature. Here, we describe an extremely rare case of an extensive spinal epidural "immature" teratoma.

\section{Case Report}

A girl was born at 38 weeks' gestation by cesarean section. At the patient's 1-month medical checkup, hypotonia of the lower extremities was observed. Medical follow-up was planned, but dyspnea associated with general cyanosis was noted 64 days after her birth. Intercostal retraction was obvious based on the patient's crying. Physical examination revealed complete flaccid paraplegia of the lower extremities, disappearance of the deep tendon reflex, and weakness of the anal sphincter tonus. Paresis of the upper extremities was not observed. Chest radiography revealed a large mass in the right thorax with spinal scoliosis (Fig. 1A). CT scanning revealed a large heterogeneous mass containing adipose tissue, bone, and a cyst on the right posterior mediastinum that originated from the spinal canal, which greatly compressed the right lung (Fig. 1B). Severe dyspnea prevented MRI before thoracic surgery. The se-

ABBREVIATIONS SET $=$ spinal epidural teratoma.

SUBMITTED November 30, 2017. ACCEPTED April 18, 2018.

INCLUDE WHEN CITING Published online July 6, 2018; DOI: 10.3171/2018.4.PEDS17676. 

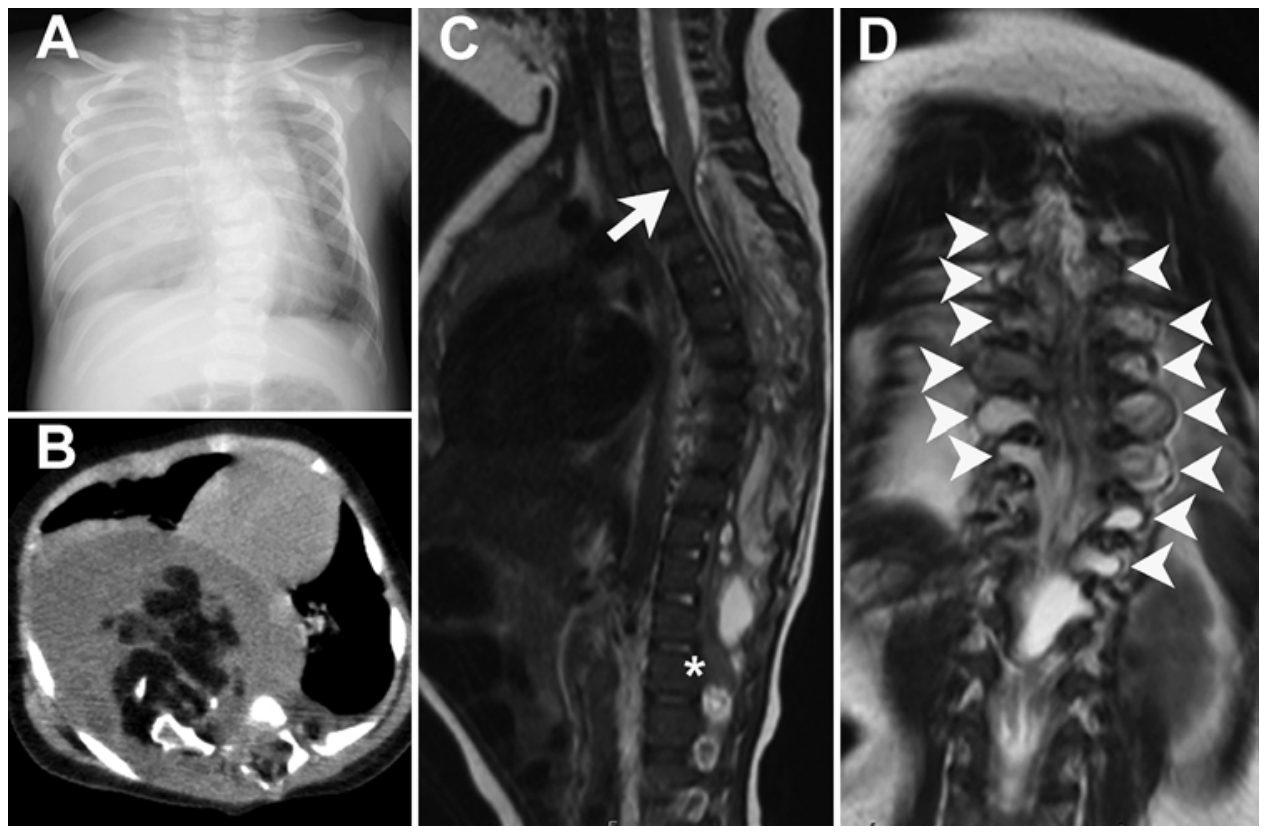

FIG. 1. A: Chest radiograph showing a right thoracic mass and scoliosis. B: Chest CT scan revealing a huge heterogeneous posterior mediastinal tumor occupying the spinal canal. C: Sagittal T2-weighted MR image showing that the cervical to thoracic spinal cord is markedly compressed anteriorly (arrow). The lower thoracic spinal cord is difficult to identify. The conus medullaris can be seen below the tumor (asterisk). D: Coronal T2-weighted MR image revealing that the tumor extends through multiple intraspinal foramina to the mediastinum (arrowheads).

rum $\alpha$-fetoprotein and human chorionic gonadotropin levels were normal. When the patient was 65 days of age, the right posterior mediastinal mass was removed via an emergency right thoracotomy. The tumor was cut at the level of the intervertebral foramina. Histologically, the tissue was noted to derive from all 3 germinal layers, incompletely differentiated tissue with $<10 \%$ neuroepithelial tissue was observed, and the pathological diagnosis was grade I immature SET (Fig. 2).

The patient's dyspnea improved after thoracic surgery, but she experienced obstructive pneumonia of the right upper lobe. Furthermore, MRI revealed that the tumor rem-

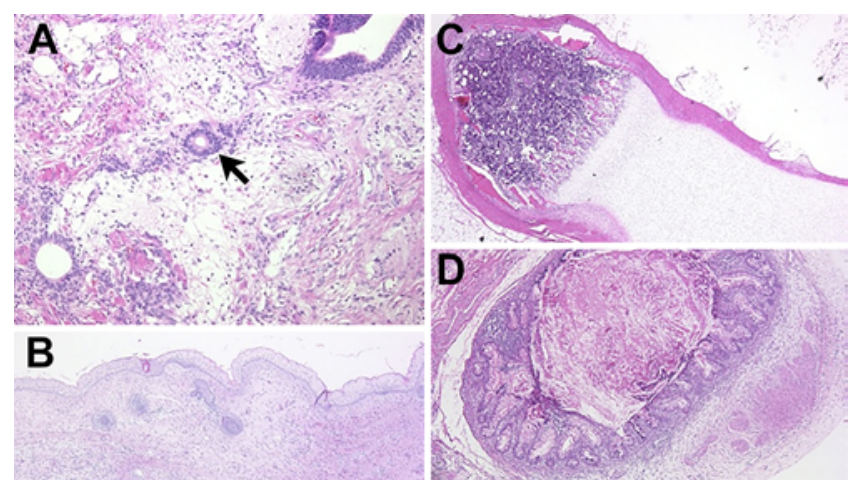

FIG. 2. Photomicrographs. The histological examination was consistent with grade I immature teratoma. The teratoma contained tissues that were derived from all 3 germinal layers. A: Foci of immature neuroepithelial tissue (<10\%) (arrow). B: Stratified squamous epithelium and hair follicles. C: Bone with bone marrow tissue. D: Gastrointestinal glandular epithelium and smooth muscle. $H$ \& E, original magnification $\times 100(A)$; $\times 40(B-D)$. Figure is available in color online only. nant originated from the posterior epidural space in the thoracic spine, causing anterior compression of the spinal cord and extending along the 14 vertebrae from C7 to L1. It also extended through multiple intervertebral foramina bilaterally to the posterior mediastinum (Fig. 1C and D).

When the patient was 90 days old and after the obstructive pneumonia was cured, the SET was removed via an open-door laminotomy from C7 through L2. The well-encapsulated, elastic hard tumor was dissected from the dura mater relatively easily (Fig. 3A). However, the extended tumor was anchored to the intervertebral foramina, and thus, internal debulking of the tumor with a cavitation ultrasonic surgical aspirator and resection of the tumor at the level of intervertebral foramina was required (Fig. 3B). After resection of the tumor in the spinal canal, the opened vertebral arches were replaced and sutured. Paralysis of the lower extremities slightly improved. Because histological examination revealed a mature teratoma without an immature component, the patient was discharged without adjuvant chemotherapy or radiotherapy at 120 days of age. However, the posterior mediastinal tumor remnant rapidly regrew, extending into the spinal epidural space (Fig. 4B), and the lower extremities exhibited flaccid paraplegia. An additional tumor resection in the spinal canal was performed via a re-laminotomy from T3 to T10 at 247 days of age. Because the patient's scoliosis made it difficult to identify the vertebral laminae that we needed to open, the procedure was assisted intraoperatively using a navigation system (Curve, Brainlab AG). Postoperatively, the patient's lower extremities exhibited little improvement (Fig. 4C). A bilateral thoracoscopic resection of the tumor of the posterior mediastinum was performed on the left side at 325 days of age and on the right side 3 weeks later. 


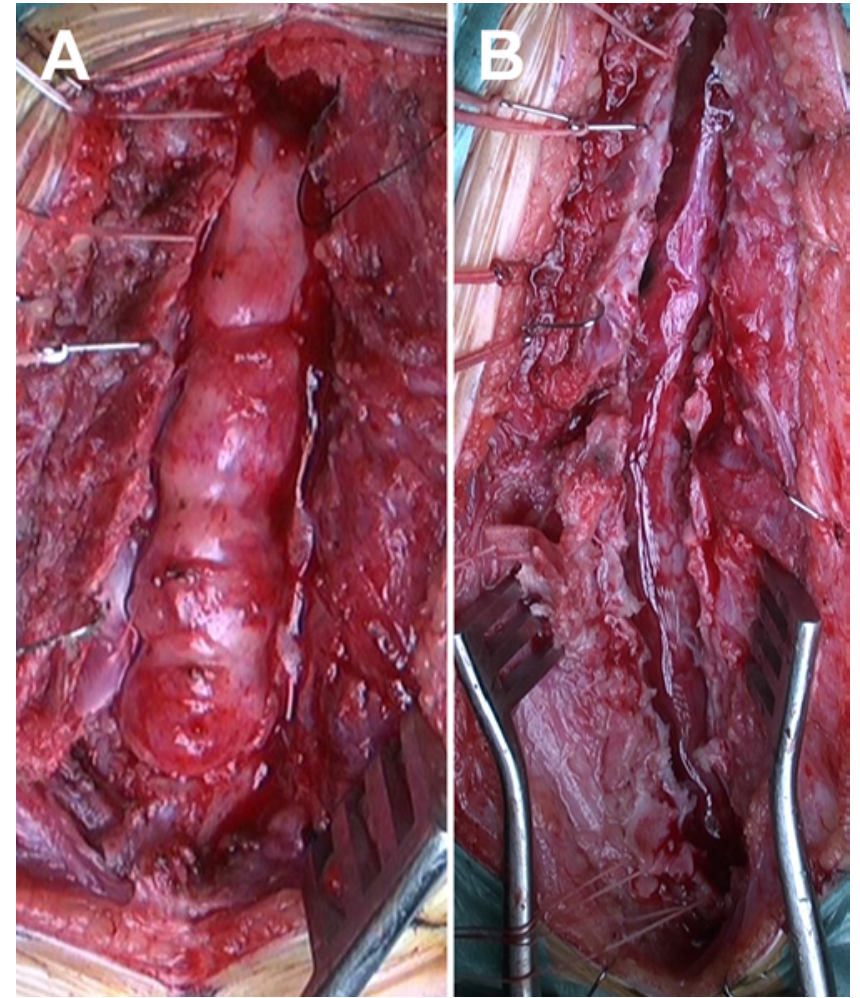

FIG. 3. Intraoperative photographs of the initial laminotomy detailing the right open-door laminotomy and yellowish elastic hard tumor rising from the spinal canal (A). A subtotal resection was performed, and no intradural extension was observed (B). Figure is available in color online only.

At 30 months after the last surgery, the residual tumor in the bilateral posterior mediastinum, which remained unchanged in terms of size, was still detectable. Severe bi- lateral flaccid paraplegia had not improved, and the patient could not void urine voluntarily. The scoliosis had gradually progressed (Cobb angle of $94^{\circ}$ ), which made it difficult to evaluate the interval change of the tumor.

\section{Discussion}

We reviewed the literature for cases of SET occurring in infants and summarized the characteristics of these cases in Table $1 ., 1,4,8,11-13,15$ We included teratomas inside the spinal canal without intradural extension, but excluded the intraspinal extension of the sacrococcygeal, retroperitoneal, and mediastinal teratomas. Several authors have reported that, with the exception of those originating from the sacrococcygeal region, spinal teratoma is rare. ${ }^{14,17}$ However, the incidence is much higher in infants and children, accounting for about $5 \%-10 \%$ of spinal tumors. ${ }^{3,5,5,10}$ Spinal teratoma includes spinal intradural teratoma and SET, and $11 \%$ of spinal teratomas have been reported to occur in the epidural region. ${ }^{12}$ SETs are less common among spinal teratomas.

Except for extensive tumors, neurological symptoms improve with tumor resection. Long-standing medullary compression is thought to be a reason that symptoms do not improve in extensive SET. ${ }^{8}$ Because slow-progressing, nonspecific physical symptoms are misleading, there is a delay in the diagnosis of most spinal cord tumors.7 While $25 \%-30 \%$ of children with a spinal cord tumor experience recurrent episodes of back pain, 7 infants cannot articulate this.

Baysefer et al. reported 8 spinal epidural tumors in a series of 20 spinal tumors and mentioned that the most common cause of nontraumatic paraparesis in children is compression of the spinal cord by epidural tumor deposits. ${ }^{3}$ In our review, paraparesis was a common presentation
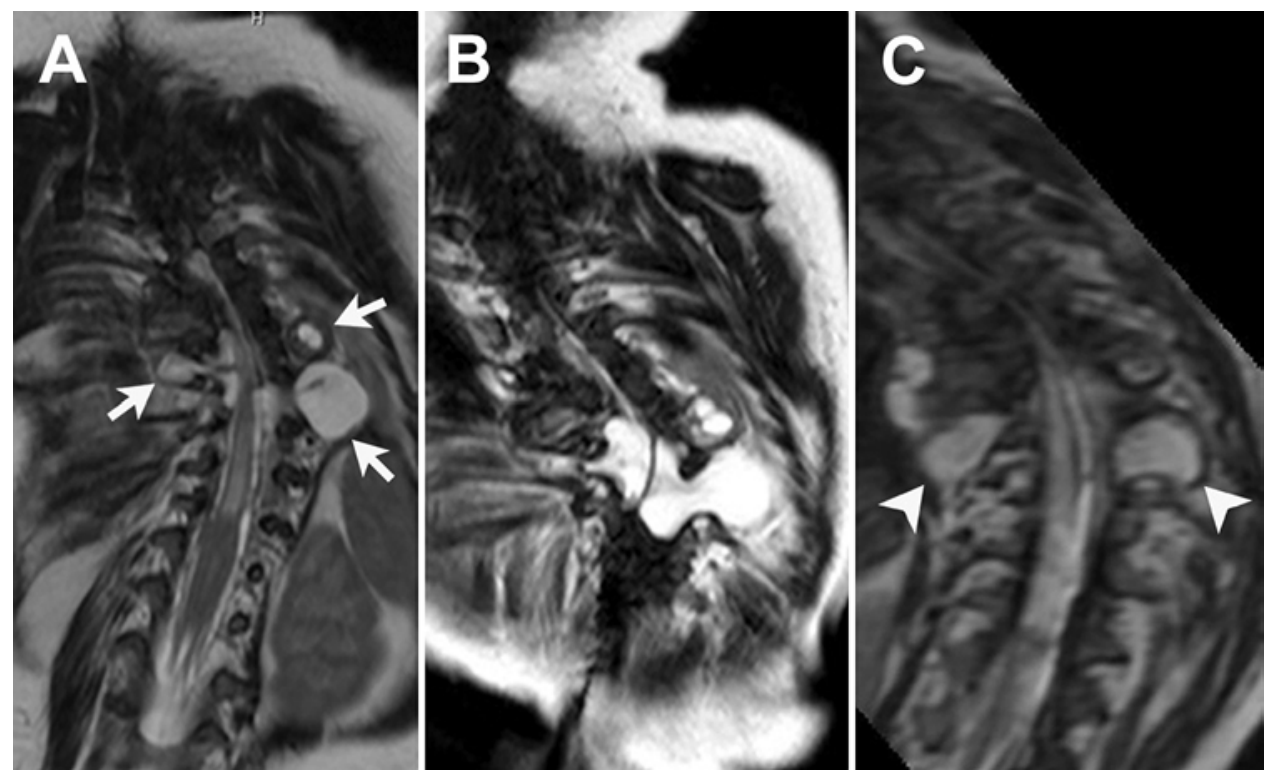

FIG. 4. Serial coronal T2-weighted MR images. A: The residual tumor is seen at the right T7-8, left T7-8, and left T8-9 intervertebral foramina (arrows), even when an intraspinal component was not observed on the postoperative MR image. B: The residual posterior mediastinal tumor shows regrowth and extension into the spinal epidural space. C: Although the intraspinal tumor was removed, the spinal cord shows severe atrophy, and the residual tumors at the posterior mediastinum (arrowheads) were resected by bilateral endoscopic thoracotomy. Serial MR images revealed the gradual progression of scoliosis. 
TABLE 1. Characteristics of cases with SETs in infants

\begin{tabular}{|c|c|c|c|c|c|c|c|c|c|c|}
\hline $\begin{array}{l}\text { Authors } \\
\text { \& Year }\end{array}$ & Age, Sex & Clinical Presentation & Level & Shape & Resection & $\begin{array}{c}\text { No. } \\
\text { of } \\
\text { Ops }\end{array}$ & Regrowth & Pathology & $\begin{array}{l}\text { Outcome } \\
\text { of Motor } \\
\text { Function }\end{array}$ & $\begin{array}{c}\text { Spinal } \\
\text { Deformities }\end{array}$ \\
\hline $\begin{array}{l}\text { Murovic et al., } \\
1986\end{array}$ & 0 days, $M$ & $\begin{array}{l}\text { Paraplegia, hypesthe- } \\
\text { sia, abdominal mass }\end{array}$ & $\mathrm{T} 10-12$ & Extensive & Subtotal & 5 & Yes & Mature & NA & $\begin{array}{l}\text { L1 destruc- } \\
\quad \text { tion }\end{array}$ \\
\hline $\begin{array}{l}\text { Razack \& Page } \\
\quad 1995\end{array}$ & 8 days, $F$ & Slightly inverted feet & Lumbar & Round & Total & $3^{*}$ & No & Mature & NA & SNS \\
\hline $\begin{array}{l}\text { Kaneko et al., } \\
1999\end{array}$ & 33 days, $\mathrm{M}$ & $\begin{array}{l}\text { Paraplegia, hypesthe- } \\
\text { sia, dyspnea }\end{array}$ & C5-L5 & Extensive & Subtotal & 6 & Yes & Mature & $\begin{array}{l}\text { Little improve- } \\
\text { ment }\end{array}$ & $\begin{array}{l}\text { Severe } \\
\text { scoliosis }\end{array}$ \\
\hline Acar et al., 2003 & $7 \mathrm{mos}, \mathrm{F}$ & $\begin{array}{l}\text { Paraparesis, hypes- } \\
\text { thesia }\end{array}$ & T6-8 & Dumbbell & Total & 1 & No & Mature & Improved & NA \\
\hline Choi et al., 2004 & $8 \mathrm{mos}, \mathrm{M}$ & Paraparesis & T2-4 & Round & Total & 1 & No & Mature & Improved & NA \\
\hline Park et al., 2010 & 19 mos, $M$ & Paraparesis & T8-10 & Dumbbell & Total & 1 & No & Mature & Improved & NA \\
\hline Quon et al., 2014 & $21 \mathrm{mos}, \mathrm{M}$ & Paraparesis & T3-10 & Dumbbell & Total & 1 & No & Mature & Improved & NA \\
\hline Present case & 64 days, $F$ & $\begin{array}{l}\text { Paraplegia, hypesthe- } \\
\text { sia, dyspnea }\end{array}$ & C7-L1 & Extensive & Subtotal & 5 & Yes & $\begin{array}{l}\text { Immature } \\
\text { (grade I) }\end{array}$ & $\begin{array}{l}\text { Little improve- } \\
\text { ment }\end{array}$ & $\begin{array}{l}\text { Severe } \\
\text { scoliosis }\end{array}$ \\
\hline
\end{tabular}

NA = not available; SNS = split notochord syndrome.

*Including ventriculoperitoneal shunt placement and colostomy.

in infants with SET. In particular, patients with extensive tumors demonstrated complete and flaccid paraplegia. Severe spinal cord compression in extensive SET results in severe motor dysfunction. Neurogenic tumors, including neuroblastoma, are the most common cause of epidural tumors in children; ${ }^{18}$ however, SET is important in the differential diagnosis of paraparesis in pediatric patients. Therefore, pediatric and neurosurgical clinicians should consider spinal teratoma in the differential diagnosis when encountering patients with progressive motor weakness, gait disturbance, and muscle rigidity in the lower extremities. Paresthesia and hypesthesia are less common in SET.

Radiological examination is used to delineate tumor shape, ${ }^{2,15}$ in our review, 6 of 8 SETs extended to the paraspinal regions through the intervertebral foramina as a dumbbell shape. A simple round SET shape was only reported in 2 cases. Among the 6 dumbbell-shaped cases, some of the tumor was extended throughout the spinal canal and/or was a huge paraspinal mass.

Our case is the first report of an immature teratoma that originated from the spinal epidural space. There are differences between the treatment of a pure mature teratoma and that of a teratoma with malignant historical features or germ cell elements. Therefore, histological examination is crucial for definitive diagnosis. The malignant elements may respond to chemotherapy or radiation therapy, but mature or benign elements do not. ${ }^{6}$ Grade I immature teratomas are not considered high-grade malignant tumors, but close monitoring for tumor regrowth is required in extensive tumors that cannot be resected in a single surgery. Resection seems to have a crucial role in the treatment of teratomas without malignant elements. The previously reported 7 cases were mature teratomas. Park et al..$^{12}$ reviewed 170 cases of spinal teratoma, including 13 SETs, and only 3 were spinal intradural immature teratomas. In the present case, initial resection specimens indicated immature teratoma, but specimens from other surgeries indicated mature teratoma, without the immature component.
This may be because of total resection or spontaneous maturation of the immature component. In fact, Shaffrey et al. reported 2 cases in which central nervous system immature teratomas subsequently matured. ${ }^{16}$

Resection is the first choice of treatment in patients with an extensive SET. However, it is quite difficult to completely remove an extensive tumor in one surgery, and multistage surgery is often required. ${ }^{8}$ Therefore, planning staged surgery, close monitoring of recurrence, and the long-term management of spinal deformity including scoliosis are strongly recommended. Further study and the accumulation of similar cases are required to establish a treatment strategy for this rare condition.

\section{References}

1. Acar O, Güney O, Eser O: Epidural thoracal teratoma in a 7-month-old girl. Childs Nerv Syst 19:126-128, 2003

2. Basmaci M, Hasturk AE, Pak I: Cystic mature teratoma of the thoracic region in a child: an unusual case. J Neurosci Rural Pract 2:186-189, 2011

3. Baysefer A, Akay KM, Izci Y, Kayali H, Timurkaynak E: The clinical and surgical aspects of spinal tumors in children. Pediatr Neurol 31:261-266, 2004

4. Choi SJ, Choi HJ, Hong JT, Woo HK, Sung JH, Lee SW, et al: Intraspinal extradural teratoma mimicking neural sheath tumor in infant. Childs Nerv Syst 20:123-126, 2004

5. DeSousa AL, Kalsbeck JE, Mealey J Jr, Campbell RL, Hockey A: Intraspinal tumors in children. A review of 81 cases. J Neurosurg 51:437-445, 1979

6. Fujimaki T: Central nervous system germ cell tumors: classification, clinical features, and treatment with a historical overview. J Child Neurol 24:1439-1445, 2009

7. Huisman TA: Pediatric tumors of the spine. Cancer Imaging 9 (Special issue A):S45-S48, 2009

8. Kaneko M, Ohkawa H, Iwakawa M, Ikebukuro K: Extensive epidural teratoma in early infancy treated by multi-stage surgery. Pediatr Surg Int 15:280-283, 1999

9. Kumar R, Singh V: Intramedullary mass lesion of the spinal cord in children of a developing milieu. Pediatr Neurosurg 40:16-22, 2004 
10. Matson DD, Tachdjian MO: Intraspinal tumors in infants and children; review of 115 cases. Postgrad Med 34:279-285, 1963

11. Murovic JA, De Armond S, Nagashima T, Edwards MS, Hoshino T: Cell kinetics analysis in a case of teratoma of the thoracic spine. J Neurosurg 65:331-334, 1986

12. Park SC, Kim KJ, Wang KC, Choe G, Kim HJ: Spinal epidural teratoma: review of spinal teratoma with consideration on the pathogenesis: case report. Neurosurgery 67:E1818E1825, 2010

13. Quon JL, Grant RA, Huttner AJ, Duncan CC: Thoracic epidural teratoma: case report and review of the literature. Clin Med Insights Pathol 7:15-20, 2014

14. Rasmussen TB, Kernohan JW, Adson AW: Pathologic classification, with surgical consideration, of intraspinal tumors. Ann Surg 111:513-530, 1940

15. Razack N, Page LK: Split notochord syndrome: case report. Neurosurgery 37:1006-1008, 1995

16. Shaffrey ME, Lanzino G, Lopes MB, Hessler RB, Kassell NF, VandenBerg SR: Maturation of intracranial immature teratomas. Report of two cases. J Neurosurg 85:672-676, 1996

17. Slooff JL: Primary Intramedullary Tumors of the Spinal Cord and Filum Terminale. Philadelphia: Saunders, 1964
18. Spacca B, Giordano F, Donati P, Genitori L: Spinal tumors in children: long-term retrospective evaluation of a series of 134 cases treated in a single unit of pediatric neurosurgery. Spine J 15:1949-1955, 2015

\section{Disclosures}

The authors report no conflict of interest concerning the materials or methods used in this study or the findings specified in this paper.

\section{Author Contributions}

Conception and design: Yoshioka. Acquisition of data: Yoshioka, Shimokawa. Analysis and interpretation of data: Shimokawa. Drafting the article: Yoshioka. Critically revising the article: Shimokawa, Kawashima, Abe. Reviewed submitted version of manuscript: Masuoka, Izaki, Nakahara, Sakata. Administrative/ technical/material support: Yoshioka. Study supervision: Abe.

\section{Correspondence}

Fumitaka Yoshioka: School of Medicine, Saga University, Saga, Japan.yoshiokf@cc.saga-u.ac.jp. 